Invasive Plant Science and

Management

www.cambridge.org/inp

\section{Research Article}

Cite this article: Otto $\mathrm{N}$ and Brunson $\mathrm{M}$ (2021) Cross-boundary weed management in protected area-centered ecosystems: how can it work and what makes it harder to achieve? Invasive Plant Sci. Manag 14: 183-189. doi: $10.1017 /$ inp.2021.24

Received: 12 May 2021

Revised: 27 July 2021

Accepted: 28 July 2021

First published online: 2 August 2021

Associate Editor:

Jacob N. Barney, Virginia Tech

Keywords:

California; collaboration; interviews; landscape level; national parks

\section{Author for correspondence:}

Mark Brunson, Department of Environment and Society, Utah State University, Logan, UT 84322-5215 (Email: Mark. Brunson@usu.edu)

\title{
Cross-boundary weed management in protected area-centered ecosystems: how can it work and what makes it harder to achieve?
}

\section{Natalie Otto ${ }^{1}$ and Mark Brunson ${ }^{2}$ (1)}

${ }^{1}$ Graduate Research Assistant, Department of Environment and Society, Utah State University, Logan, UT, USA and ${ }^{2}$ Professor, Department of Environment and Society, Utah State University, Logan, UT, USA

\begin{abstract}
Invasive species management in natural landscapes is generally executed at the scale of independent jurisdictions, yet the ecological processes and biodiversity to be protected from invasion occur over large spatial scales and across multiple jurisdictions. Jurisdictional land boundaries can influence the flows and dynamics of ecological systems, as well as the social systems that exist in these complex landscapes. Land management entities in large, protected area-centered ecosystems may use different approaches to address cross-boundary management challenges. To understand these differing strategies and their effects on cooperative invasive plant management, we interviewed employees with federal, county, and state agencies, research organizations, nonprofits, and local stakeholder groups in two national parks and their surrounding lands in California, USA. Although all participants stressed the importance of working together, they did so along a continuum of strategies ranging from simple communication to coordination of independent efforts to active collaboration. Barriers to collaboration can be categorized as originating within or externally to the management unit, including limited resources, differing agency priorities, paperwork requirements, and lack of support by higherlevel managers. Strategies to reduce barriers depend on where they originate.
\end{abstract}

(c) The Author(s), 2021. Published by Cambridge University Press on behalf of the Weed Science Society of America. This is an Open Access article, distributed under the terms of the Creative Commons Attribution licence (https:// creativecommons.org/licenses/by/4.0/), which permits unrestricted re-use, distribution, and reproduction in any medium, provided the original work is properly cited.

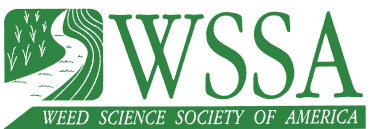

\section{Introduction}

Protected areas (PAs) such as national parks, wildlife refuges, and wilderness areas are designated to conserve and maintain biodiversity and ecosystems (Dickson et al. 2017). However, PAs are just one part of much larger ecosystems. Most are not designated by considering ecological completeness or function (Sacre et al. 2019), but rather by characteristics such as land use, scenic value, political feasibility, or ease of management (Pressey 1994). Due to this lack of a holistic view, PAs may not effectively protect the species and processes they were originally created to preserve (Davis and Hansen 2011).

By delineating "protected area-centered ecosystems" (PACEs), scientists have tried to conceptualize the span of ecological processes that continue outside the bounds of PAs. PACEs are the larger zones around PAs, wherein ecological flows occur on a landscape scale (DeFries et al. 2007). While the PACE concept addresses the geographic scope of ecological function, it does not consider how to effectively manage these large areas comprising many individually managed properties, all of which have a variety of different uses and management priorities. The challenge is to find ways to participate in cross-boundary stewardship for healthy ecosystems and the threats these ecosystems face. Among the most pressing of these threats is the presence and spread of nonnative invasive species (NNIS) (Schulze et al. 2018).

Historically, broadscale management of NNIS has been a cause of conflict in the field of biodiversity conservation because of the difficulties of cooperation among the parties responsible for different jurisdictions (Stokes et al. 2006). Managers and landowners may express polarized viewpoints depending on how they are differently affected or on how they perceive NNIS impacts in the context of other issues, such as fire and fuel management. Organizational missions likewise may influence support for the ways in which NNIS management is conducted or the amount of resources allocated to the problem.

In this study, we focus on management of nonnative invasive plants. Because invasive plants are not constrained by property boundaries, if they are not controlled in one jurisdiction they will continue to be a problem for the neighboring jurisdiction - an important consideration in and around protected areas. Invasive plant control is a complex problem in PACEs, because the success of control will require cooperative interactions among all parties within the patchwork of ownerships that comprise a PACE (Epanchin-Niell and Wilen 2014). Understanding the kinds of activities taking place in PACEs, as well as successful and failed attempts at 


\section{Management Implications}

The ecosystem services provided by protected areas (PAs) such as national parks are susceptible to impacts of nonnative invasive species invasions that can result from land-use activities outside their borders. Almost all PAs are parts of much larger landscapes featuring a patchwork of different landownerships managed under differing regulations and objectives. Because invasive species move across landscapes, the ecological integrity of these natural areas can be protected through cross-boundary cooperative weed management, but only if barriers caused by divergent land uses and missions can be surmounted. Using interviews of employees in and around Lassen Volcanic and Sequoia-Kings Canyon National Park in California, USA, we discerned the extent of cooperation among neighboring entities, the factors that led to their success, and how and why collaborative efforts failed.

While participants reported communicating about infestations and coordinating their independent control efforts, active collaboration between land management entities was rare. Reasons for this included mismatched priorities, different geography, too few resources, and insufficient support from upper management. Some barriers can be directly addressed within the management unit. For example, to resolve priority mismatches and to share or leverage resources, collaboration can be improved internally by engaging with a third-party, boundary-spanning organization such as a weed management area or conservation nonprofit. Formal agreements can help to engender trust among organizations and stakeholders and ensure commitment to mutual goals. To indirectly influence external barriers such as higher-level policies or funding decisions, public education may be most effective.

cross-boundary cooperation, may be critical to formulating effective management strategies at a landscape scale.

Cooperative interaction is an umbrella term, wherein communication, coordination, and collaboration reside along a continuum (Tait and Brunson 2021; Yaffee 1998). Cooperation reflects various behaviors and interactions that encourage a mutually beneficial relationship with one or more people from different organizations (Yaffee 1998). At the low end of the continuum, communication requires the least effort. Communication involves recognizing and being aware of others' priorities and goals, sharing knowledge, and talking about others' activities and current projects, but does not necessarily lead to collective or mutually beneficial action. Coordination establishes a higher level of integration between entities (Keast et al. 2007) and often involves an interaction with another entity in which information sharing or participation is advantageous in achieving independent goals, while also not conflicting with the goals of the other entity involved (Yaffee 1998). Generally, coordination occurs when there is a need to align, to address priorities more effectively (Litterer 1973), but entities and activities remain autonomous (Cigler 1999). Collaboration is when participants work together to address complex problems and collective interests that cannot be accomplished independently (Mattessich et al. 2001). The partnerships and relationships that exist in collaboration entail trust, taking risks, sharing resources, planning together to an extent where at times "a blurring of the boundaries between organizations" occurs (Keast et al. 2007). When problems arise that are deemed of high importance and that cannot be satisfactorily managed by a single organization, the likelihood of collaboration is predicted to increase (Gray 1985).
To mount a productive response to nonnative plant invasions in the face of these challenges, resource managers must understand the barriers to cooperative management and how to overcome them in order to create active partnerships with neighbors wherein common goals can be aligned (Simpson et al. 2009). To elucidate these barriers and efforts to surmount them, we studied cross-boundary invasive plant management in two PACEs in California, USA.

\section{Materials and Methods}

\section{Study Areas}

PACE boundaries and their respective polygons are determined by six criteria: hydrologic flows, atmospheric flows, disturbances, crucial habitats, effective size, and human impacts (Hansen et al. 2011). The scope of data collection for this research included three national parks in California: Lassen Volcanic (abbreviated by the National Park Service [NPS] as LAVO), Sequoia, and Kings Canyon. The latter parks adjoin and are encompassed within a single PACE (SEKI).

The SEKI PACE, in the southern Sierra Nevada mountain range $100 \mathrm{~km}$ east of the city of Fresno, spans parts of three counties (Tulare, Fresno, and Inyo counties) and three national forests (Sierra, Sequoia, and Inyo). Sequoia and Kings Canyon national parks, along with the U.S. Forest Service's (USFS) John Muir Wilderness, represent the protected core of this PACE. Also within the PACE management mosaic are lands administered by the Bureau of Land Management (BLM), U.S. Fish and Wildlife Service, private and corporate landowners, the federal Bureau of Indian Affairs, cities and counties, and nongovernmental organizations. The largest portion of the PACE is NPS, USFS, and BLM land. In total, the PACE circumscribes approximately 1.9 million hectares (4.3 million acres).

The LAVO PACE is smaller, at approximately 376,357 hectares (930,000 acres) within Tehema, Plumas, Lassen, and Shasta counties in northern California. It is centered on Lassen Volcanic National Park, 74\% of which is designated wilderness. This PACE includes three protected areas: Lassen Volcanic National Park and two USFS wildernesses: Thousand Lakes and Caribou. In addition to the national park, the PACE covers the Lassen National Forest, BLM, state, county, and private land, much of which is owned by timber companies.

\section{Data Collection}

We used a qualitative case study approach involving semistructured interviews, which allowed the subjects to talk about the topics they deemed important. An interview guide was developed consisting of 26 questions (Supplementary Appendix S1). Interviews were conducted in August to November 2019. Interview durations ranged from 22 to $90 \mathrm{~min}$. Initially, interviewees were identified by contacting jurisdiction offices within each PACE to identify persons with direct responsibility for invasive plant management. As part of each interview, the lead author employed "snowball sampling" (Biernacki and Waldorf 1981) by asking to be referred to others who might have valuable insight, especially persons not employed by their jurisdiction. This method continued until saturation was reached, that is, new information or themes were no longer being obtained from subsequent interviews (Guest et al. 2006).

This approach yielded 20 interviews before achieving saturation: 8 for LAVO and 12 for SEKI. Interviewees were employed 
by the USFS, NPS, U.S. Department of Agriculture-Natural Resources Conservation Service, California Department of Agriculture, California Department of Transportation, University of California Cooperative Extension, Sequoia Riverlands Trust, and local weed management areas. It is not uncommon, when studying a relatively narrow topic in a small geographic area, to have a sample size as small as 20 (Charmaz 2006; Mason 2010). There is a point of diminishing returns to interview research, as more data do not necessarily lead to more information (Ritchie et al. 2003). In this study, focusing on a landscape dominated by large expanses of public land, only a small number of individuals are responsible for invasive species management and control. Therefore, despite the small sample, we believe we connected with a reasonable proportion of the total population of invasive species professionals in the two PACEs.

Interviews provided comprehensive information about how agencies within a PACE deal with NNIS, the challenges they face in management, and their participation in cooperative interaction. Initial interview questions focused on individuals' backgrounds in natural resource management, then progressed to specific questions about invasive plants, perceived differences across jurisdictional boundaries, and cooperative management successes and barriers.

\section{Analysis}

The qualitative data obtained in this matter were analyzed to identify themes: ideas, topics, and patterns of meaning that arose repeatedly in the interviews. To effectively analyze the data and allow themes to emerge, first we completed word-for-word transcriptions of the interviews. Transcripts were studied independently, then ATLAS.ti qualitative analysis software (ATLAS.ti Qualitative Data Analysis, Berlin, Germany) was used to code and highlight significant statements, sentences, and quotes that provided a description of how the participants have experienced working together with other agencies or landowners. We identified themes through an inductive, data-driven approach, using detailed readings of raw data to derive recurring concepts through interpretations made from the data (Thomas 2006). In doing so, we were able to develop "clusters of meaning" by identifying the important common experiences of the participants (Creswell and Poth 2016), which helped us to conceptualize underlying patterns. This method yielded a total of 130 codes and 1,053 quotations.

\section{Results and Discussion}

While many common themes emerged from the interviews, four were the most relevant to understanding the threats of invasive plants and barriers to invasive plant control. These included: (1) ecological concerns surrounding invasive plants, (2) the challenges of cooperative invasive plant management, (3) the perceived benefits and importance of collaboration; and (4) the level of cooperative interaction that is occurring between different agencies and across jurisdictional lines. These also offer insights in how participants within each PACE could increase momentum for collaborative invasive plant management across jurisdictions.

\section{Ecological Concerns}

All participants agreed invasive plants have significant ecological impacts on the lands they manage. Differences in responses between the two PACEs were negligible. Habitat quality

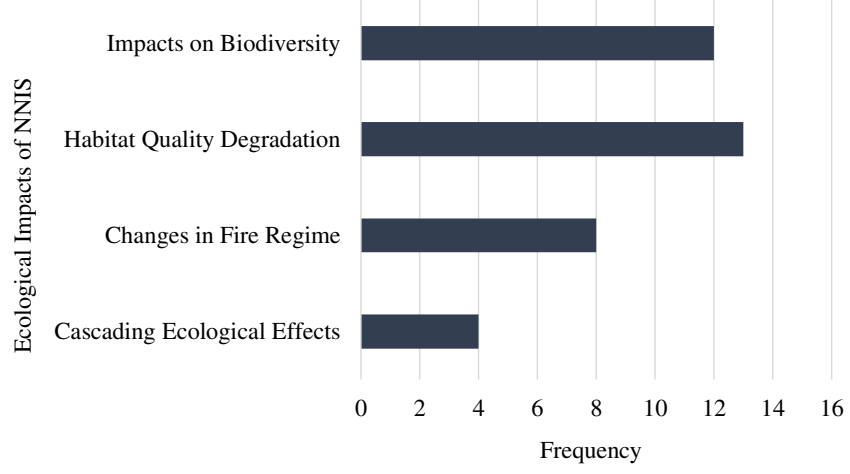

Figure 1. Number of interviewees who referenced specific ecological and managementrelevant impacts of invasive plants in their jurisdictions. Total frequencies exceed 20 (participants) due to multiple impacts being referenced in single interviews.

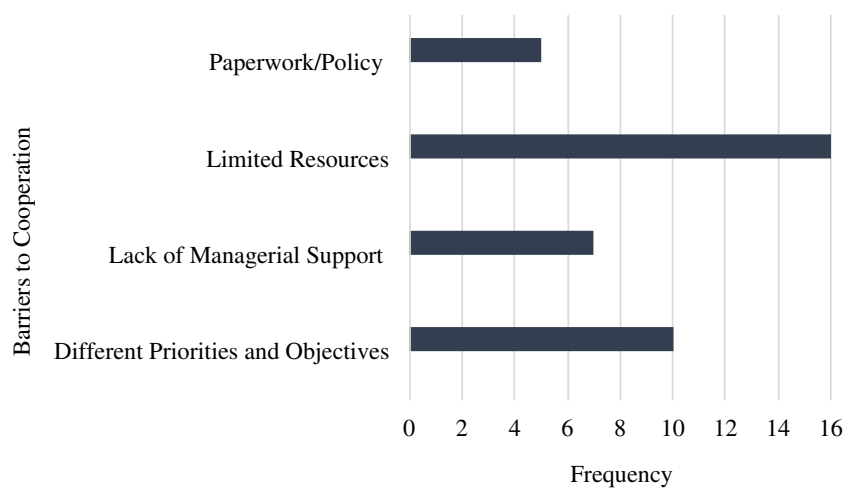

Figure 2. Number of interviewees who referenced specific barriers to cooperative interaction in their work. Total frequencies exceed 20 (participants) due to multiple barriers being referenced in single interviews.

degradation was the most commonly noted ecological consequence of nonnative plant invasion (Figure 1), followed by impacts on biodiversity, changes in fire and disturbance regimes, and their cascading ecological effects. These findings all correspond to well-known adverse effects of nonnative plant invasions in natural ecosystems. One participant described the effects:

"Weeds change fuel models, they push ecological communities over ecological thresholds that they can't get back over again, they change the fire return interval, they crowd out native species, which has a whole cascade of impacts on invertebrates, on birds and wildlife, and they have impacts on recreation as well."

Participants from both SEKI and LAVO specifically mentioned cheatgrass (Bromus tectorum L.) as a big issue, particularly in relation to shifting disturbance and fire regimes.

\section{Challenges of Cooperative Management}

The barriers to invasive plant control and cooperative management that were most often reported included: (1) limited resources (funding, time, personnel), (2) differing management priorities and priority species between entities, (3) lack of managerial support and education, and (4) paperwork and policy barriers (Figure 2). Resource limitation was the most frequently reported barrier, with funding and lack of trained staff and time emerging as the most common themes. Participants noted that they had many other activities to prioritize, as their job responsibilities often were not solely dedicated to invasive plant management. One participant stated, "You just don't have the time for [collaboration] 
when you have one botanist for the entire forest." An NPS interview subject explained, "I think it's just a question of resources to acres. We have way higher resources for fewer acres whereas the Forest Service has squat for millions of acres." Appropriate funding to allocate to invasive plants for all entities within a PACE was seen as crucial for being able to cooperate in balanced collaborative partnerships.

The second most frequently cited barrier was differing management priorities and land-use objectives. The priorities and missions within a PACE often differ in focus and scope: county agriculture departments are mandated to manage all Class A noxious weeds, NPS must protect natural and cultural resources, and the USFS and BLM are directed to manage land for a variety of uses. This dichotomy is described by one participant, "I think [collaboration is] more driven by the Park Service. Because again, we have the mission to maintain the 'native-ness' if you will. Forest Service has a mission to graze and create more feet of lumber." The USFS tendency to prioritize fire management and fuel reduction above invasive plant management was cited often, despite research demonstrating the role of invasive annual grasses in fire occurrence and intensity (D'Antonio and Vitousek 1992; Kerns et al. 2020). One participant described, "[USFS is] so concerned about the fuel issue and fires; it's a prioritization thing. When a town burns down, nobody cares about invasive species." In addition to different management priorities, subjects also reported that their toppriority weeds were often different from those of their neighbors as well.

Lack of managerial support was a barrier especially relevant to federal agencies and an obvious source of frustration for some federal participants. Federal entities are responsible for public interests and are consequently susceptible to public influence, which can help or hinder funding for invasive plant management. In a state where wildfire is an especially difficult problem, public concern about the role of land management may force agencies such as the BLM and USFS to be even more concerned with fuel and fire issues than elsewhere in the western United States. Interviewees working for federal entities argued for better education as a tool for leveraging support for invasive plant management: "You've got too many undereducated, miseducated, or non-educated general public and politicians that just don't have a clue. And so, you're never going to get funding until you can raise up the understanding level of everyone."

Paperwork and policy barriers were recognized by participants from both PACEs. Frustration was directed at policy barriers such as National Environmental Policy Act (NEPA) rules that require environmental assessments to use herbicides on any infestation on federal land. A federal employee explained, "A lot of times bureaucracy for whatever reason impedes us; it takes a lot of work to push paper just to be able to do a simple task." Participants not working for a federal entity conveyed similar irritation when describing attempts at cooperation. A non-federal employee expressed, "For as good-intentioned as [USFS and BLM] are, they get bogged down with paperwork, and the work doesn't get done because of that." USFS employees believed that invasive plant management and cooperative partnerships would be more attainable with streamlined herbicide-use documents and NEPA approval. Some USFS interviewees stated that with all their other job responsibilities to consider, the time and effort required for approval are often not worth it, leaving no other option but hand pulling and other physical methods of control that are ineffective at larger scales.

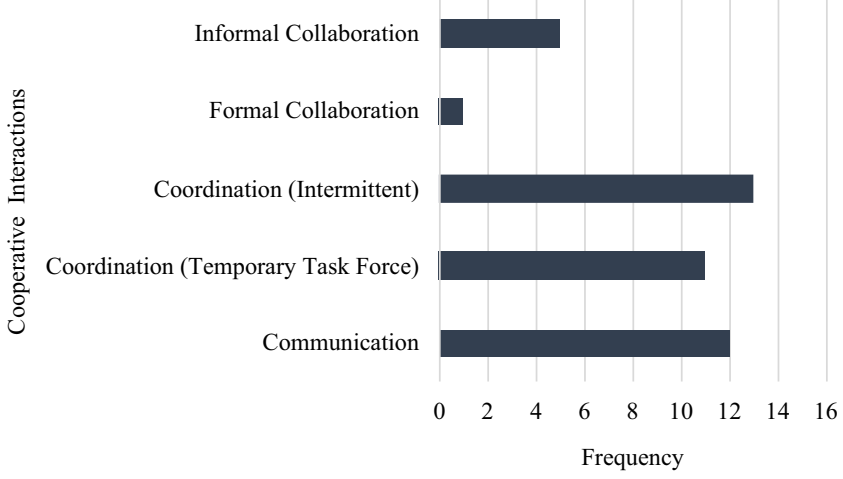

Figure 3. Number of interviewees who reported participating in specific types of cooperative interaction. Total frequencies exceed 20 (participants) due to multiple cooperative actions being referenced in single interviews.

\section{Perceived Benefits and Importance of Collaboration}

Discussion of benefits and importance of collaboration focused on information sharing. Regular, in-person meetings among individuals with invasive plant management responsibilities allow opportunities for networking and getting pertinent people's contact information: "I learn what person and what agency I have to deal with and who are the contacts, so it's a lot of opening doors and keeping the ball moving on controlling weeds." Another participant mentioned the importance of these meetings for education and knowledge sharing: "We really didn't have to reinvent the wheel, we shared our successes and our failures, and sharing the failures were just as valuable as the successes."

\section{Level of Cooperative Interaction}

Respondents reported using communication, two kinds of coordination, and one instance of ongoing collaboration between entities (Figure 3). Communication, while the easiest form of cooperation to achieve, was the second most commonly mentioned cooperative interaction. Agencies from across the region come together one to three times annually for meetings, conferences, or trainings to discuss natural resource-related issues.

Coordination can take various forms, from partnerships that are informal and loosely defined with a limited scope and independent action, to more formal relationships that focus on tackling issues concerning large-scale systems to accomplish common goals (Mandell and Steelman 2003). Here we identified two of Mandell and Steelman's (2003) coordination categories, temporary task force, and intermittent coordination, with the latter being the most common form of cooperative behavior overall. Intermittent coordination occurs when policies and procedures of two or more entities are adjusted to accomplish a mutual objective. The level of commitment and interaction is low, and resource sharing is minimal.

Intermittent coordination occurred when one jurisdiction noticed a patch of weeds adjacent to their boundary. This jurisdiction then contacted it neighboring jurisdiction, relayed the exact location of the weeds, and asked that it be treated before it had the chance to cross over the boundary. In most cases, the jurisdiction with the weeds was previously unaware of the weed population, became informed, and treated the site. This is considered coordination, rather than communication, because two or more different entities consulted one another, planned, and altered their independent activities to achieve a mutual objective. The action 
carried out by one party was carried out in a manner that supported those of another, but operating procedures of those parties remained independent. A participant described this interaction:

"Lassen Volcanic National Forest, Lassen Volcanic National Park, and Lassen County we try to coordinate with, as well as with the other agencies on our border. Controlling the spread is important by consulting with all the agencies and saying hey this is on your side, can you take care of it before it gets onto our side?"

Temporary task force coordination was the third overall most common type of cooperative interaction reported across both PACEs. A temporary task force is similar to intermittent coordination but is differentiated by a smaller scope of focus, time allotment, and tasks that are to be accomplished. A temporary task force is formed independently by one entity to accomplish a specific goal and disbands when that goal is achieved. Resource sharing is limited in scope as well in this form of coordination (Mandell and Steelman 2003). In this research, a task force was formed to carry out "favors," most commonly carried out by the NPS for the USFS.

These "favors" occurred when weed populations were present at a boundary area: Rather than consulting with their neighbors and asking them to take care of it, jurisdiction personnel would contact the entity with the weeds and ask permission to cross the boundary to treat the weeds. One NPS participant reported an informal agreement whereby NPS assumed responsibility for a certain amount of land on a neighbor's property, due to an imbalance of resources and incentive to treat invasive plants. Favors were always done by the entity with the most resources to allocate to invasive plant management; in this study, that entity was nearly always the NPS. NPS officials in both PACEs explained that they "hopped the fence" into abutting USFS land to treat weed populations, to differing degrees. One participant testified to a more sporadic type of ad hoc activity, "I've emailed their district Ranger and said 'hey, we found this on your side, do you care if we ...?' And she goes 'nope, just go treat it."' Another NPS employee described a more involved form of coordinated activities on USFS land:

"We have a cooperative agreement with Sequoia National Forest. They have populations just across our boundary, within 2 miles, and they don't have the resources to go after them, so we've pulled those populations within 2 miles of the boundary and are managing them with our Park Service crews."

The type of cooperative interaction that occurred the least across both PACEs was collaboration. Informal collaboration was reported to occur sporadically, but formal collaboration was only confirmed by one county-employed interviewee in SEKI. This individual worked with a weed management area that had been able to remain more active and involved, despite limited federal funding. This participant stated that it was her job to be "a kind of coordinator and grant writer, so funding sourcing and coordinating; helping with big picture management and use of resources, to know what's going on with the money and then help our land managers more strategically use their resources." Collaboration is the most time- and labor-intensive form of cooperative interaction (Tait and Brunson 2021), and it is likely that the involvement of an individual with a coordination role was what made the collaboration feasible.

\section{Implications for Improved Cooperative Management}

In multi-ownership landscapes, the beliefs, values, and motivations of each stakeholder contribute to a highly complex pattern of landscape conditions (Stanfield et al. 2002), creating challenges for ecosystem management. The need for cooperation across ownership boundaries has been acknowledged for many years (e.g., Brunson 1998), yet public and private entities alike face obstacles to forming and sustaining cooperative relationships. Management that spans jurisdictions is mainly restricted to informal communication and intermittent coordination, while formal processes such as transdisciplinary research, co-production and co-management, or joint planning and decision making are scarce. Findings from the greater Lassen and Sequoia-Kings Canyon ecosystems show that the entities working in natural resource management in these regions are confronted with four primary challenges to cooperative invasive plant management: limited resources, differing priorities and objectives, lack of managerial support, and paperwork/policy requirements.

Cooperative management is an ongoing process, a continual building of relationships between different organizations and individuals who can identify and strive to address common goals together. While missions and priorities may differ in focus, size, or scope between entities in a PACE, organizations in natural resource management tend to have some overlapping goals, and all entities care about managing the harmful effects of invasive plants. The objective is to determine what kind of cooperative interaction is best for each entity and their neighbors and to foster that relationship so that effective landscape-scale management can be achieved. More involved forms of cooperative behaviors can be attained in the future if and when resources become available, or priorities more closely align.

To identify opportunities for overcoming barriers, we first identified the sources of those barriers - that is, whether they originate internally within the management unit directly responsible for invasive plant management, or externally because of agency-wide policies or other factors that lie outside the management unit (Figure 4). Viewed through this lens, we categorized internal barriers as those related to allocation of resources within the unit, as well as local management priorities and supervisor support. Barriers that originate externally include agency-wide missions and regulations, congressional or agency-wide funding decisions, lack of high-level support within the agency, and public opposition to control actions. The source of a barrier (external vs. internal) influences the type of strategy that may best be employed to address the barrier. We identified opportunities for land managers to use bottom-up, locally initiated approaches to assist in overcoming the barriers they identified. These recommendations are compatible with suggestions from previous research on cooperative management (Epanchin-Niell et al. 2010; Novoa et al. 2018; Yaffee 1998).

Proactive entities can find it beneficial to employ a "boundary spanner," that is, an individual (or organization) who facilitates the process of knowledge exchange between multiple entities in a specific, often complex social setting, and whose full-time role is to act as expert intermediary (Bednarek et al. 2018). By leveraging each partner's strengths while accommodating each partner's internal constraints, boundary spanners can help collaborating entities address barriers associated with limited resources, mismatches between agency missions or local management priorities, and agency regulations. They are able to cultivate trust, build relationships, determine the different priorities and limitations, and suggest multiple options and perspectives that align with the goals of all entities involved. Frequently when boundary spanners are employed to address specific issues, they are housed within middle-level organizations such as county weed management programs, regional invasive species control organizations, or local 


\section{EXTERNAL CHALLENGES \\ STRATEGY}

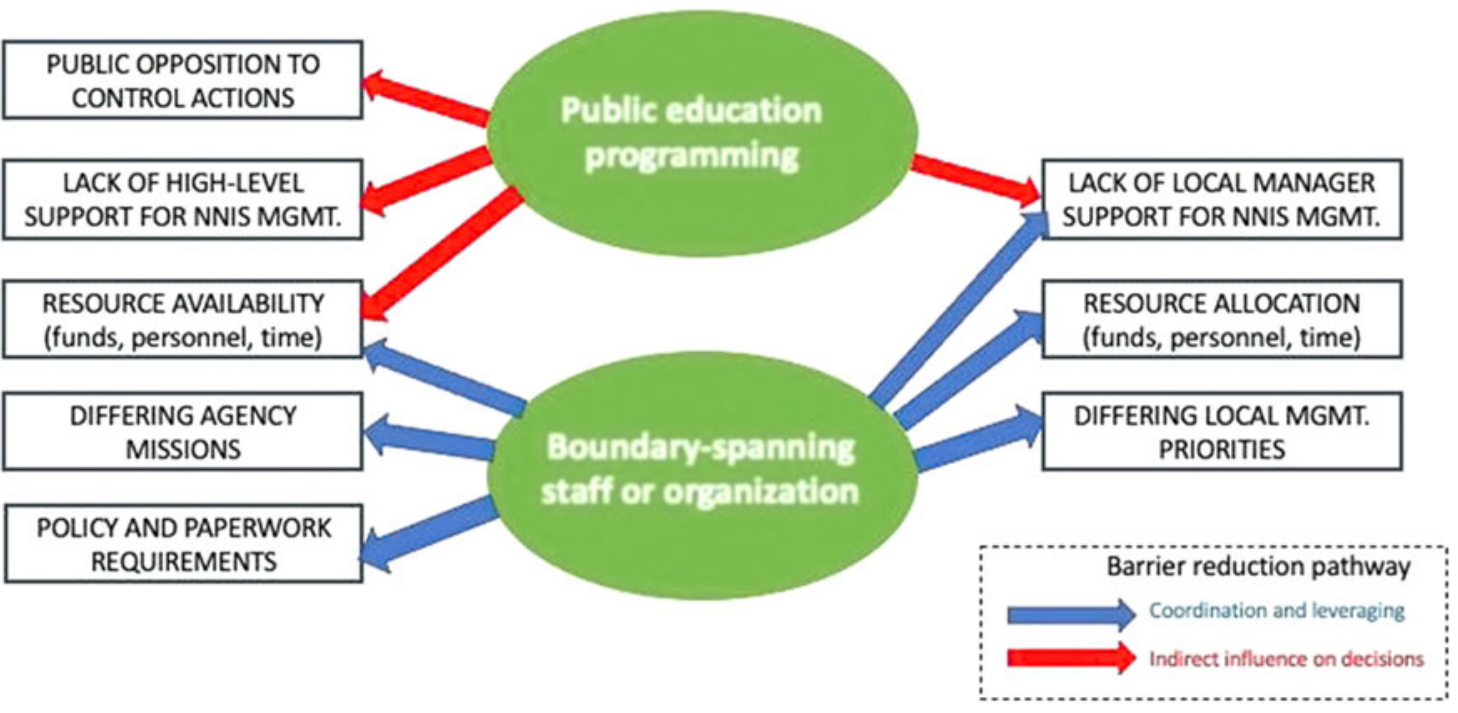

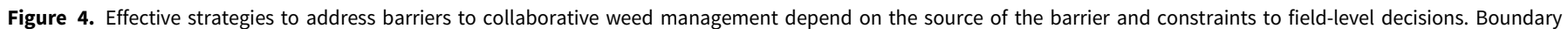

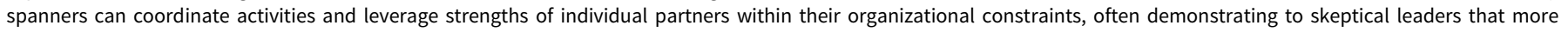

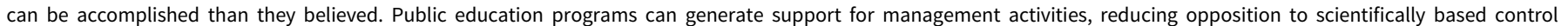
strategies, while showing decision makers at local or higher levels that invasive species should have higher priority. NNIS, nonnative invasive species.

resource conservation districts whose goal is to foster cooperative management and encourage participation in weed prevention (Epanchin-Niell et al. 2010; Hershdorfer et al. 2007).

Where a boundary-spanner cannot always be available, cooperative action can be aided by formal planning processes led by an ad hoc outside facilitator (Novoa et al. 2018). Facilitation can help those involved to reach consensus on the approaches to be adopted for cross-boundary management (Lampe 2001). Formal agreements can help to engender trust among organizations and stakeholders by declaring all parties' commitment to mutual goals (Novoa et al. 2018). In offices where leadership gives lower priority to NNIS issues relative to other agency activities, the presence of a formal agreement makes it more difficult to shift resources away from invasive plant management once a commitment has been made.

Often, however, the barriers to collaborative weed management originate far from the unit charged with that management. Regulatory requirements such as those associated with NEPA are government-wide and cannot be ignored at the local level. Funding decisions similarly are made at an agency-wide level based on decisions by Congress or state legislatures. Even so, bottom-up effort can indirectly influence those decisions by promoting public awareness of the deleterious effects of invasive species, thereby strengthening weed programs (Hershdorfer et al. 2007). Heightened public awareness and involvement can influence federal support, because concern from the general public can increase pressure on government to address the issue (Schneider and Ingram 1990). Individuals who are concerned about invasive plants are more likely to obtain more information about them (Tidwell and Brunson 2008). Thus, when the public and other stakeholders become more knowledgeable and involved, their interest in invasive plant management is likely to rise, potentially also influencing the practices of organizations that do not prioritize such management (Henriques and Sadorsky 1999).
Emergent threats related to invasive plants on different jurisdictions within PACEs are complex; therefore, appropriate solutions will need to be similarly complex (Lien et al. 2020). Regional cooperative ecosystem management can find resolutions to the issues that are analogous with the challenges (Schwartz et al. 2019). As land-use changes intensify, climate change alters the landscape, and invasive plant species expand their ranges, cooperative interactions between entities will become even more paramount and may help shift the balance and reduce costs associated with managing biological invasions (Simpson et al. 2009). While participants in our study identified many challenges to overcome to be able to participate in collaborative partnerships, they also all believed any form of cooperative management with neighbors would be fruitful and expressed a desire for more.

This research builds upon existing literature that has investigated cooperative management between different entities in a natural resource context, the challenges of cooperation, and the potential ways to remediate these barriers. We examined PACEs and the lived experiences of 20 individuals working with invasive plants in these areas within a single state; future research on crossboundary stewardship should investigate other PACEs outside California or even the United States to evaluate which of these results are applicable at broader scales and which may be more context dependent. We further recommend exploring collaborative invasive plant management successes as well as failures to further advance our understanding of cooperative weed management.

Supplementary material. To view supplementary material for this article, please visit https://doi.org/10.1017/inp.2021.24

Acknowledgments. We thank all the interview participants from the SEKI and the LAVO PACEs who agreed to let us interview them. Funding for this research was from the National Science Foundation (grant no. 1617309). Additional support was from the Utah Agricultural Experiment Station (UAES). Approved as UAES paper no. 9479. No conflicts of interest have been declared. 


\section{References}

Bednarek AT, Wyborn C, Cvitanovic C, Meyer R, Colvin RM, Addison PF, Close SL, Curran K, Farooque M, Goldman E, Hart D, Mannix H, McGreavy B, Parris A, Posner S, et al. (2018) Boundary-spanning at the science-policy interface: the practitioners' perspective. Sustain Sci 13:1175-1183

Biernacki P, Waldorf DAN (1981) Snowball sampling problems and techniques of chain referral and sampling. Sociol Method Res 10:141-163

Brunson MW (1998) Social dimensions of boundaries: balancing cooperation and self-interest. Pages 65-86 in Knight RL, Landres PB, eds. Stewardship across Boundaries Washington DC: Island Press

Charmaz K (2006) Constructing Grounded Theory: A Practical Guide through Qualitative Analysis. Los Angeles: Sage. 208 p

Cigler B (1999) Preconditions for the emergence of multicommunity collaborative organizations. Rev Policy Res 16:86-102

Creswell JW, Poth CN (2016) Qualitative Inquiry and Research Design: Choosing Among Five Approaches. Los Angeles: Sage. 459 p

D’Antonio CM, Vitousek PM (1992) Biological invasions by exotic grasses, the grass/fire cycle, and global change. Annu Rev Ecol Evol Syst 23: 63-87

Davis CR, Hansen AJ (2011) Trajectories in land use change around U.S. national parks and challenges and opportunities for management. Ecol Appl 21:3299-3316

DeFries R, Hansen A, Turner BL, Reid R., Liu J (2007) Land use change around protected areas : management to balance human needs and ecological function. Ecol Appl 17:1031-1038

Dickson B, Albano CM, Mcrae BH, Anderson JJ, Theobald DM, Zachmann LJ, Sisk TD, Dombeck MP (2017) Informing strategic efforts to expand and connect protected areas using a model of ecological flow, with application to the western United States. Conserv Lett 10: 564-571

Epanchin-Niell RS, Hufford MB, Aslan CE, Sexton JP, Port JD, Waring TM (2010) Controlling invasive species in complex social landscapes. Front Ecol Environ 8:210-216

Epanchin-Niell RS, Wilen JE (2014) Individual and cooperative management of invasive species in human-mediated landscapes. Am J Agric Econ 97: $180-198$

Gray B (1985) Conditions facilitating interorganizational collaboration. Hum Relat 38:911-936

Guest G, Bunce A, Johnson L (2006) How many interviews are enough? An experiment with data saturation and variability. Field Method 18: $59-82$

Hansen AJ, Davis CR, Piekielek N, Gross J, Theobald DM, Goetz S (2011) Delineating the ecosystems containing protected areas for monitoring and management. BioScience 61:363-373

Henriques I, Sadorsky P (1999) The relationship between environmental commitment and managerial perceptions of stakeholder importance. Acad Manag J 42:87-99

Hershdorfer ME, Fernandez-Gimenez ME, Howery LD (2007) Key attributes influence the performance of local weed management programs in the southwest United States. Rangeland Ecol Manag 60:225-234

Keast R, Brown K, Mandell M (2007) Getting the right mix: unpacking integration meanings and strategies. Int Public Manag J 10:9-33

Kerns BK, Tortorelli C, Day MA, Nietupski T, Barros AMG, Kim JB, Krawchuk MA (2020) Forest ecology and management invasive grasses: a new perfect storm for forested ecosystems? For Ecol Manag 463:117985
Lampe M (2001) Mediation as an ethical adjunct of stakeholder theory. J Bus Ethics 31:165-173

Lien A, Baldwin E, Franklin K (2020) Collective action and invasive species governance in southern Arizona. Rangeland Ecol Manag 74: 151-164

Litterer JA (1973) The Analysis of Organizations. 2nd ed. New York: Wiley. $757 \mathrm{p}$

Mandell M, Steelman T (2003) Understanding what can be accomplished through interorganizational innovations: the importance of typologies, context and management Strategies. Public Manag Rev 5:197-224

Mason M (2010) Sample size and saturation in PhD studies using qualitative interviews. Forum Qualitative Sozialforschung/Forum: Qualitative Social Research 11(3), 10.17169/fqs-11.3.1428

Mattessich P, Murray-Close M, Monsey B (2001) Collaboration: What Makes It Work? St. Paul, MN: Amherst H. Wilder Foundation. 104 p

Novoa A, Shackleton R, Canavan S, Cyb C, Davies SJ, Dehnen-Schmutz K, Fried J, Gaertner M, Geerts S, Griffiths CL, Kaplan H, Kumschick S, LeMaitre DC, Measey GJ, Nunes AL, et al. (2018) A framework for engaging stakeholders on the management of alien species. J Environ Manag 205: 286-297

Pressey ARL (1994) Ad hoc reservations: forward or backward steps in developing representative reserve systems? Conserv Biol 8:662-668

Ritchie J, Lewis J, Elam G (2003) Designing and selecting samples. Pages 77-108 in Ritchie J, Lewis J, eds. Qualitative Practice Research: A Guide for Social Science Students and Researchers. Los Angeles: Sage

Sacre E, Pressey RL, Bode M (2019) Costs are not necessarily correlated with threats in conservation landscapes. Conserv Lett 12:e12663

Schneider A, Ingram H (1990) Behavioral assumptions of policy tools. J Polit 52:510-529

Schwartz MW, Redford KH, Leslie EF (2019) Fitting the US National Park Service for change. BioScience 69:651-657

Schulze K, Knights K, Coad L, Geldmann J, Leverington F, Eassom A, Marr M, Butchart SHM, Hockings M, Burgess ND (2018) An assessment of threats to terrestrial protected areas. Conserv Lett 11:e12435

Simpson A, Jarnevich C, Madsen J, Westbrooks R, Fournier C, Mehrhoff L, Browne M, Graham J, Sellers E (2009) Invasive species information networks: collaboration at multiple scales for prevention, early detection, and rapid response to invasive alien species. Biodiversity 10(2-3):5-13

Stanfield BJ, Bliss JC, Spies TA (2002) Land ownership and landscape structure: a spatial analysis of sixty-six Oregon (USA) Coast Range watersheds. Landscape Ecol 17:685-697

Stokes K, Neill KP, Montgomery W, Dick JT, Maggs C, McDonald R (2006) The importance of stakeholder engagement in invasive species management: a cross-jurisdictional perspective in Ireland. Biodivers Conserv 15: 2829-2852

Tait MK, Brunson MW (2021) Evaluating cooperative interactions and the roles organizations play in cross-boundary stewardship. Soc Natur Resour (online first). https://www.tandfonline.com/doi/full/10.1080/08941920.2021. 1900964 ?src

Thomas DR (2006) A general inductive approach for analyzing qualitative evaluation data. Am J Eval 27:237-246

Tidwell LS, Brunson MW (2008) Volunteering to manage rangeland weeds. Rangelands 30(4):19-24

Yaffee S (1998) Cooperation: a strategy for achieving stewardship across boundaries. Pages 299-324 in Knight RL, Landres PB, eds. Stewardship across Boundaries Washington DC: Island Press 